\title{
Re-establishment of Gap Junctional Intercellular Communication (GJIC) between Human Endometrial Carcinomas by Prostaglandin $\mathrm{E}_{2}$
}

\author{
Scott R. Schlemmer ${ }^{a}$ and David G. Kaufman ${ }^{b}$ \\ Department of Pathology and Laboratory Medicine, University of North Carolina School of \\ Medicine, Chapel Hill, NC 27599-7295
}

\section{Abstract}

Reduced intercellular communication via gap junctions is correlated with carcinogenesis. Gap junctional intercellular communication (GJIC), between normal human endometrial epithelial cells is enhanced when endometrial stromal cells were present in culture. This enhancement of GJIC between normal epithelial cells also occurs when they are cultured in medium conditioned by stromal cells. This observation indicated that a soluble compound (or compounds) produced and secreted by stromal cells mediates GJIC in epithelial cells. Previous studies have shown that endometrial stromal cells release prostaglandin $\mathrm{E}_{2}\left(\mathrm{PGE}_{2}\right)$ and prostaglandin $\mathrm{F}_{2 a}\left(\mathrm{PGF}_{2 a}\right)$ under physiological conditions. When we evaluated the response of normal endometrial epithelial cells to various concentrations of $\mathrm{PGE}_{2}$, we found enhanced GJIC with $1 \mathrm{nM} \mathrm{PGE}_{2}$. This is a smaller increase in GJIC than that induced by medium conditioned by stromal cells. When the extracellular concentration of $\mathrm{PGE}_{2}$ was measured after incubation with stromal cells, it was found to be similar to the concentrations showing maximal GJIC between the normal epithelial cells. When indomethecin was used to inhibit prostaglandin synthesis by stromal cells, GJIC was reduced but not eliminated between normal endometrial epithelial cells. These observations suggest that although $\mathrm{PGE}_{2}$ secreted by stromal cells is an important mediator of GJIC between the epithelial cells, it is not the sole mediator. Transformed endometrial epithelial cells did not demonstrate GJIC even in the presence of stromal cells. However, we were able to re-establish GJIC in transformed epithelial cells when we added $\mathrm{PGE}_{2}$ to the cells. Our findings show that $\mathrm{PGE}_{2}$ may serve as an intercellular mediator between stromal and epithelial cells that regulates GJIC in normal and malignant epithelial cells. This suggests that maintenance of GJIC by preserving or replacing $\mathrm{PGE}_{2}$ secretion by endometrial stromal cells may have the potential to suppress carcinogenesis in endometrial epithelial cells.

\footnotetext{
(c) 2012 Elsevier Inc. All rights reserved.

${ }^{b}$ Corresponding Author: David G. Kaufman, M.D., Ph.D., Department of Pathology and Laboratory Medicine, School of Medicine, CB\# 7525, University of North Carolina at Chapel Hill, Room 514, Brinkhous-Bullitt Building, Chapel Hill, NC 27599-7525, Telephone: (919) 966-1396, FAX: (919) 966-5046, uncdgk@med.unc.edu.

${ }^{a}$ Current Address: Scott R. Schlemmer, Ph.D., CPhT, Department Chair - Pharmacy Technician, National College, 27557 Chardon Road, Willoughby Hills, OH 44092
}

Conflicts of Interest Statement

The authors declare that there are no conflicts of interest.

Publisher's Disclaimer: This is a PDF file of an unedited manuscript that has been accepted for publication. As a service to our customers we are providing this early version of the manuscript. The manuscript will undergo copyediting, typesetting, and review of the resulting proof before it is published in its final citable form. Please note that during the production process errors may be discovered which could affect the content, and all legal disclaimers that apply to the journal pertain. 


\section{Keywords}

Endometrium; Prostaglandin; Gap Junctional Intercellular Communication; Epithelial-Stromal Interaction; Human; Cancer

\section{Introduction}

With about 47,000 new cases per year, endometrial carcinoma is the invasive cancer of the female genital tract with the highest incidence in women in the United States (American Cancer Society, 2012). Even though these cancers are commonly detected early in their natural history and therapeutic measures effectively treat, and even cure, a large fraction of these cancers, still about 8,000 American women die of this disease each year (American Cancer Society, 2012). While the incidence and death rate from endometrial cancer varies over time the approximate proportion of women succumbing to this disease has not changed greatly. This continuing toll of endometrial cancer deaths despite the current armamentarium of surgical, radiologic and chemotherapeutic treatments points out the need for further investigations of endometrial cancer that may reveal new therapeutic options. We recognize that estrogen exposure not counteracted by progesterone is the primary etiologic risk factor for developing this disease but we do not know conclusively the mechanism of pathogenesis by which endometrial cancer is caused by estrogen.

One of the hallmarks of endometrial cancer that is used as one of the criteria for its diagnosis is the relationship between endometrial glands and the intervening stroma. In the normal endometrium endometrial glands are separated by ample quantities of loose stroma predominantly populated by endometrial stromal cells. The transition to endometrial cancer is typically accompanied by the loss of most of the stroma between glands yielding back-toback apposition of malignant glands. The common type of endometrial cancer is preceded by a form of hyperplasia thought to have a high risk of progression to cancer ("Endometrial Intraepithelial Neoplasia" (EIN)), and this reduction of stroma also is seen at this stage of the natural history of endometrial cancer (Mazur, 2005). An objective analysis of endometrial hyperplasias by computerized imaging techniques distinguished EIN, based largely on reduction of stromal cells between glands. Diagnosis of EIN by morphometric criteria proved to be a better predictor of progression to cancer than traditional classifications of hyperplasia (Baak, et al., 2005). The decreased proportion of stromal cells between glands in EIN suggests that mechanisms regulating homeostatic stromal-epithelial cell interactions are defective in endometrial cancer and its pre-invasive precursor.

Over a number of years our laboratory has studied the regulation of homeostatic stromalepithelial cell interactions in human endometrium using human endometrial stromal and epithelial cells in co-cultures. We showed that endometrial epithelial cells grown on "Matrigel" would generate well-formed glands with polarized cells and a central lumen (Rinehart, et al., 1988). When colonies of stromal and epithelial cells were co-cultured on Matrigel and grew to contact each other they formed a basement membrane-like structure, with dense extracellular fibrillar protein networks and hemi-desmosomes at the basal surface of epithelial cells at the interface (Hopfer et al., 1994). Stromal cells embedded in Matrigel reduce the proliferation of epithelial cells as measured by ${ }^{3} \mathrm{H}$-thymidine uptake, cell counting, and labeling of DNA with BrdU in situ (Arnold et al., 2001). This inhibitory effect is not observed when the stromal cells are grown on plastic, suggesting that the interaction between stromal cells and Matrigel influences paracrine factors produced by stromal cells. When normal human foreskin fibroblasts (NHF-1 cells) or medium conditioned by them were used in place of endometrial stromal cells in parallel studies they had no influence on endometrial epithelial cell growth. This eliminates the possibility that these results were due 
to depletion of the medium by the stromal or NHF-1 cells or that these effects were not specific to endometrial stromal cells.

This co-culture system has been validated further by demonstrating the ability of epithelial cells to respond to hormonal stimulation. In endometrial tissue reconstructed in this manner, appropriate hormonal responses to estrogen and progesterone regulating epithelial cell proliferation and differentiation of these cells depends on the presence of stromal cells together with epithelial cells (Arnold et al., 2001). In the presence of progesterone, normal endometrial epithelial cells were shown to increase their secretion of glycodelin when cocultured with stromal cells. We found that stromal cells mediate the proliferative effect of estrogens (or anti-proliferative effect of progestins) on endometrial epithelial cells by their secretion of paracrine growth factors. This interaction could be reproduced with medium conditioned by stromal cells in place of direct co-culture. Moreover, we found that only stromal cells grown on extracellular matrix (ECM) could mediate the estrogen regulation of epithelial cell proliferation (Arnold et al., 2002). The studies using conditioned medium point out the role of paracrine growth factors secreted by stromal cells as regulators of epithelial cell proliferation.

We subsequently immortalized a primary stromal cell population by transducing a human telomerase reverse transcriptase subunit (hTERT) (Barbier et al., 2005). This cell line, named SHT290, has been shown to substitute for normal primary stromal cells in the coculture system, and can mediate the hormonally regulated proliferative response in the same manner. We used this system to recreate the progestagenic effects of the hormone replacement therapy drug Tibolone in endometrium in vivo, and showed that it results from the metabolism of the drug by co-cultures of endometrial cells (Barbier et al., 2008). This pattern of metabolism is not demonstrated by epithelial cells cultured in the absence of stromal cells; Tibolone was also estrogenic in mono-cultures. This is further evidence that endometrium reconstructed in these co-cultures reproduces the normal endometrium in vivo better than endometrial mono-cultures.

Another aspect of endometrial epithelial-stromal interaction that we studied is gap junctions, the semi-permeable transmembrane pores formed between adjacent cells that permit the exchange of molecules smaller than one kilodalton (KDa) [Larsen and Risinger, 1985; Spray, 1985; Revel et al., 1985]. Gap junctions are formed by hemichannels composed of six protein subunits referred to as connexins in both adjacent cells which align and assemble into a channel between the cells called a connexon [Beyer, 1990]. This aspect of cell interaction is important because several groups of investigators have shown a correlation between reduced functioning of gap junctions, known as gap junctional intercellular communication (GJIC), and carcinogenesis and metastatic potential, primarily in cells of epithelial origin [Cronier, L., et al., 2009; Fitzgerald et al., 1994; Klann et al., 1989; Leithe, et al., 2006; Mesnil, et al., 2005; Nicholson et al., 1988; Trosko, 2003; Vinken, et al., 2009;]. Consistent with this, our earlier studies on gap junctions showed an inverse correlation between connexin 43 ( $\mathrm{Cx} 43$ ) protein expression in endometrial cells and the degree of progression in grade of endometrial epithelial carcinoma in vitro and in vivo [Schlemmer et al., 1999]. Conversely, studies with normal endometrial epithelial cells showed that coculture with normal endometrial stromal cells increases Cx 43 expression in the epithelial cells. Subsequent studies showed that GJIC was induced in normal epithelial cells when they were co-cultured with stromal cells; this effect could not be reproduced when malignant epithelial cells were cultured with stromal cells [Schlemmer and Kaufman, 2000].

Furthermore, ultrastructural studies showed that interactions between stromal and epithelial cells in the normal human endometrium caused an increase in the size and number of gap junctions in epithelial cells [Roberts et al., 1988]. 
In this report we consider how human endometrial stromal cells mediate their effects on GJIC between endometrial epithelial cells and whether this effect could be mediated by medium conditioned by stromal cells. Further, based on reports that exogenous application of prostaglandin $\mathrm{E}_{1}$ [Radu et al., 1982] increased GJIC between mammalian cells we evaluated whether prostaglandins could replace stromal cells or stromal cell-conditioned medium on GJIC in endometrial epithelial cells and whether prostaglandins could influence GJIC between endometrial cancer cells.

\section{Material and Methods}

\section{Materials}

Indomethecin and prostaglandins $\mathrm{E}_{1}, \mathrm{E}_{2}$, and $\mathrm{F}_{2 \mathrm{a}}$ were purchased from Sigma-Aldrich (St. Louis, MO).

\section{Endometrial Tissue Isolation}

Samples of uterine tissue were obtained from patients at the University of North Carolina Hospitals. Fragments of endometrial tissue are collected and placed in ice cold F12 media with antibiotics, minced into $1 \mathrm{~mm}$ pieces, and enzymatically digested with collagenase I and III (Sigma-Aldrich., St. Louis, MO) overnight at $4^{\circ} \mathrm{C}$. Endometrial epithelial and stromal cells were separated by differential centrifugation at $4^{\circ} \mathrm{C}$ using $1000 \mathrm{~g}$ for $3 \mathrm{~min}$ to isolate epithelial cells and $2500 \mathrm{~g}$ for $5 \mathrm{~min}$ to isolate stromal cells.

\section{Tissue Culture}

Endometrial epithelial cell lines used for these studies were FEEC (Fetal Endometrial Epithelial Cells; immortalized with SV40 large T antigen), HEC-1A (Stage 1A endometrial carcinoma, [Kuramoto et al., 1972]), and RL-95-2 (Grade II endometrial carcinoma, [Way et al., 1983]). Normal endometrial stromal cells were obtained as described above and grown from frozen stocks maintained in our laboratory. Endometrial epithelial and stromal cells were cultured on $100 \mathrm{~mm}$ plastic dishes (Thermo Fisher Scientific, Pittsburgh, PA) coated with a 1:5 dilution of phenol-red free Matrigel (Collaborative Biomedical Products Division, BD Biosciences Discovery, Bedford, MA). The growth medium consisted of phenol-red free M199/F12 (1:1) with $2 \mu \mathrm{g} / \mathrm{ml}$ insulin. Antibiotic/antimycotic (Life Technologies, Gibco BRL Division, Gaithersburg, MD), Mitoplus (Collaborative Biomedical Products, Bedford, MA), bovine pituitary extract (Collaborative Biomedical Products, Bedford, MA), and insulin-transferrin-selenium (Boehringer-Mannheim, Indianapolis, IN) were added according to manufacturers' instructions. Phenol red was omitted to help reduce potential effects of estrogen agonists [Bindal et al., 1988]. The FEEC, HEC-1A, and RL-95-2 cell lines were chosen to represent progressive stages in the evolution of endometrial cancer. Cells were harvested while cultures were in exponential growth phase by removal of growth medium and treatment of cells with $2 \mathrm{ml}$ of Dispase (Collaborative Biomedical Products, Bedford, MA) per $100 \mathrm{~mm}$ plastic dish for $10 \mathrm{~min}$ at $37^{\circ} \mathrm{C}$. Subsequently the cells were washed with HBSS containing $10 \mathrm{mM}$ EDTA, washed again with HBSS, and then replanted on single- well LAB-TEK glass microscope slides (NUNC Division, Thermo Fisher Scientific, Pittsburgh, PA) that had been coated with a 1:5 dilution of phenol-red free Matrigel for microinjection experiments.

\section{Microinjection}

This procedure was performed in a manner similar to Ruch and Klaunig with minor modifications [Ruch and Klaunig, 1988]. Glass micropipettes were made with a Model P-87 micropipette puller (Sutter Instrument Co., Novato, CA) and backfilled with 5\% (w/v) Lucifer Yellow CH (Sigma-Aldrich Co., St. Louis, MO) in 0.1 M LiCl. Microinjections 
were performed on exponentially growing cells using a Model 5242 air pressure microinjector (Eppendorf North America Inc., Hauppauge, N.Y.) under differential interference contrast (DIC) microscopy. Photographs were taken of epifluorescent light generated from the donor and dye coupled cells $5 \mathrm{~min}$ after microinjection using a Zeiss Inverted Microscope (Carl Zeiss Co., USA, Peabody, MA). For co-cultured epithelial and stromal cells, the donor and recipient cells were distinguished from each other as described previously [Schlemmer and Kaufman, 2000].

\section{Statistical Methods}

The student's t-test was used to compare results from the microinjection experiments.

\section{$\mathrm{PGE}_{2}$ ELISA}

An ELISA analysis for $\mathrm{PGE}_{2}$ was performed with a $\mathrm{PGE}_{2}$ immunoassay kit (R\&D Systems Inc., Minneapolis, MN) according to manufacturer's directions.

\section{Results}

Figure 1 illustrates results of dye transfer experiments. Panels 1A and 1B illustrate cultures of normal epithelial cells, cultured alone in conventional medium. Panels 1C and 1D illustrate epithelial cells that were cultured using medium that was conditioned by stromal cells. Conditioning of medium was done by culturing young stromal cells in the medium for 48 hours, and then diluting it 1:1 with unconditioned medium. Panels $1 \mathrm{E}$ and $1 \mathrm{~F}$ illustrate epithelial cells that were cultured in the presence of stromal cells. The photos on the left side (panels 1A, 1C, and 1E) were taken using differential interference contrast microscopy to identify the location of the cells analyzed, and photos on the right side (panels $1 \mathrm{~A}, 1 \mathrm{C}$, and 1E) were taken using epifluorescence to demonstrate cells containing Lucifer yellow. When epithelial cells were cultured alone, dye did not spread to adjacent cells, which indicates a lack of GJIC, (panel 1B). In contrast, there was clear evidence of dye spreading to adjacent cells when the epithelial cells are exposed to media conditioned by stromal cells (panel 1D) or co-cultured with stromal cells (panel 1F). Panels 1A, 1B, 1E, and 1F were previously published [9], and are shown here only for the purpose of comparison to panels 1C and 1D. The number of cells showing dye transfer was determined for replicate experiments and the results were used as a measurement of GJIC capacity under the given experimental conditions (Table 1). These results indicate that GJIC between endometrial epithelial cells is induced by endometrial stromal cells, but the stromal cells do not have to be physically present to exert their effect on GJIC between the epithelial cells. This indicates that induction of GJIC in endometrial epithelial cells is mediated by one or more diffusible extracellular factors secreted by stromal cells. Data in Table 1 showing GJIC between epithelial cells cultured alone and with stromal cells was previously published [Schlemmer and Kaufman, 2000] and is reprinted here for the purpose of comparison with new findings.

Because prostaglandins are known to be secreted by endometrial cells and because they were known to increase GJIC between epithelial cells in other tissues, we evaluated certain aspects of prostaglandin metabolism in these endometrial cell cultures. To determine whether stromal cell cultures secreted $\mathrm{PGE}_{2}$ into the culture medium, we performed a competitive ELISA using growth medium recovered after incubation with near-confluent stromal cells for 48 hours. The results showed a $\mathrm{PGE}_{2}$ concentration of $182 \pm 23 \rho \mathrm{M}$. Next, we attempted to determine whether addition of $\mathrm{PGE}_{2}$ to culture medium could substitute for stromal cells or stromal cell conditioned medium as an inducer of GJIC in endometrial epithelial cells. Normal epithelial cells were cultured for 24 hours in growth medium to which $1 \mu \mathrm{M}, 1 \mathrm{nM}$, or $1 \rho \mathrm{M} \mathrm{PGE}_{2}$ had been added and then GJIC was assayed. As compared with epithelial cells cultured alone without $\mathrm{PGE}_{2}$, GJIC was inhibited by $1 \mu \mathrm{M}$ 
$\mathrm{PGE}_{2}$, stimulated by $1 \mathrm{nM} \mathrm{PGE} 2$, and not changed significantly by $1 \rho \mathrm{MPGE}$ (Figure 2). The results for GJIC in epithelial cells in coculture with stromal cells are shown for purposes of comparison, and are the same as epithelial cells exposed to medium conditioned by stromal cells. Further evidence for the involvement of $\mathrm{PGE}_{2}$ in controlling GJIC between normal epithelial cells and stromal cells was demonstrated by pre-treatment of a coculture of normal epithelial cells and stromal cells with $1 \mu \mathrm{M}$ of indomethecin 24 hours before microinjection. These experiments showed there was $85.5 \%$ inhibition of GJIC as compared to epithelial cells cultured alone (Figure 2).

Figure 3 illustrates dye transfer following microinjection as an indication of GJIC in transformed endometrial epithelial cells. Results show GJIC where transformed epithelial cells were cultured without $\mathrm{PGE}_{2}$ (panels $3 \mathrm{a}, 3 \mathrm{c}$, and $3 \mathrm{e}$ ) or with the concentrations of $\mathrm{PGE}_{2}$ shown to produce the maximal GJIC effect in each of the transformed epithelial cell lines $\mathrm{PGE}_{2}$ (panels 3b, 3d, and 3f). All of the photos were taken under epifluorescent illumination five minutes after microinjection. FEEC cells cultured alone failed to transfer dye between cells (panel 3a) while after treatment with $10 \mu \mathrm{M} \mathrm{PGE}_{2}$ the injected FEEC cell transferred dye to four cells (panel 3b). HEC-1A cells cultured without $\mathrm{PGE}_{2}$ did not show GJIC (panel 3c) but after treatment with $100 \mathrm{nM} \mathrm{PGE}_{2}$ the injected HEC-1A cell transferred dye to four cells (panel 3d). Similarly, untreated RL-95-2 cells did not transfer dye (panel 3e) whereas RL-95-2 cells treated with $100 \mathrm{nM} \mathrm{PGE}_{2}$ transferred dye to four adjacent cells (panel 3f). These inductive effects of $\mathrm{PGE}_{2}$ on GJIC in FEEC, HEC-1A, and RL-95-2 cells were specific in so far as treatments with $1 \mu \mathrm{M} \mathrm{PGE}_{1}$ or $1 \mu \mathrm{M} \mathrm{PGF} \mathrm{PG}_{2 a}$ did not re-establish GJIC (data not shown).

The results of studies comparing the concentration of $\mathrm{PGE}_{2}$ to the induced effect on GJIC in transformed endometrial epithelial cells are illustrated in Figure 4. These studies assess the GJIC induced in response to one-log increments in concentration of $\mathrm{PGE}_{2}$ when added to cultures of FEEC, HEC-1A, and RL-95-2 cells. Results were compared to control experiments without $\mathrm{PGE}_{2}$. All observations showed increases in GJIC that were statistically significant except at $10 \mu \mathrm{M} \mathrm{PGE}$ with the HEC-1A cells where the increase did not achieve statistical significance. The results show that GJIC can be induced in each of the three cell lines by treatments with $\mathrm{PGE}_{2}$. The maximal induction of GJIC between HEC-1A cells and between RL-95-2 cells was observed with $0.1 \mu \mathrm{M} \mathrm{PGE}_{2}$, while it required $10 \mu \mathrm{M} \mathrm{PGE} 2$ to achieve the maximal induction of GJIC in FEEC cells.

\section{Discussion}

Previous investigations have shown that intercellular communications through gap junctions is decreased in malignancies (Cronier, L., et al., 2009; Leithe, et al., 2006; Mesnil, et al., 2005; Vinken, et al., 2009; Yamasaki, et al., 1995). In previous studies we have demonstrated an abnormality of connexin expression in endometrial cancers (Schlemmer, et al., 1999). We followed this by demonstrating that intercellular communication via gap junctions was absent in endometrial epithelial cells or endometrial cancer cells when assessed in cell culture (Schlemmer and Kaufman, 2000). We showed, however, that coculture of the normal epithelial cells with stromal cells would restore intercellular communication between the endometrial epithelial cells. Therefore, interaction between stromal and epithelial cells was essential for this normal epithelial cell function. The results of this study extend our previous observations concerning the activity of GJIC in human endometrial epithelial cells. The current study shows that the stromal cells need not be physically present for GJIC to be induced. Medium in which normal endometrial stromal cells had been grown (conditioned medium) was able to substitute for stromal cells in causing an increase GJIC between normal epithelial cells. The induction appears to be mediated by one or more soluble and diffusible factors made by the stromal cells and 
secreted into their culture medium in vitro and presumably into their immediate environment in vivo. Our studies in vitro also indicate that $\mathrm{PGE}_{2}$ is one such mediator. We have shown that the stromal cells secrete $\mathrm{PGE}_{2}$ into the conditioned medium that can induce GJIC. We also have shown that treatment of cultures of normal endometrial epithelial cells with $1 \mathrm{nM}$ $\mathrm{PGE}_{2}$ can induce GJIC. Conversely, we have shown that if $\mathrm{PGE}_{2}$ production is inhibited in cultures containing stromal cells, GJIC is blocked in the epithelial cells. While treatment of normal endometrial epithelial cell cultures with 1 nanomolar (nM) $\mathrm{PGE}_{2}$ can induce GJIC, treatments with much higher $(1$ micromolar $(\mu \mathrm{M}))$ or much lower $(1$ picomolar $(\rho \mathrm{M}))$ concentrations of $\mathrm{PGE}_{2}$ inhibited GJIC or had no effect. Even at its most effective concentration, treatment of epithelial cell cultures with $\mathrm{PGE}_{2}$ restored only part of the induction of GJIC produced by stromal cells. This indicates that other factors produced by stromal cells contribute to the induction of GJIC.

Several other investigators have done studies in vitro and in vivo attempting to resolve the role of $\mathrm{PGE}_{2}$ in tumorigenesis. Studies done with human colorectal tumor tissue have documented an increase in cyclooxygenase 2 (COX-2) expression [Sano et al., 1995], and suggested that increased $\mathrm{PGE}_{2}$ production is a factor contributing to the induction of colorectal cancer. Consistent with this, studies using transgenic mice that overexpress the human COX-2 gene in their mammary glands showed tumorigenesis and metastasis in a tissue-specific manner [Lui et al., 2001]. However, increased production of $\mathrm{PGE}_{2}$ was not sufficient for mammary cancer development; this effect of increased $\mathrm{PGE}_{2}$ only occurred in the mice after three to four rounds of weaning and pregnancy. Other investigators have shown that homologous disruption of the genes coding for COX-1 or -2 expression reduced polyp formation in Min/+ mice by approximately $80 \%$ [Chulada et al., 2000]. These investigators suggested that other factors are required in addition to $\mathrm{PGE}_{2}$ for carcinogenesis, and that $\mathrm{PGE}_{2}$ is involved with malignant progression. Our results indicate that a sufficient and localized concentration of $\mathrm{PGE}_{2}$ may block GJIC between normal epithelial cells (Figure 2) at a concentration of $1 \mu \mathrm{M}$. It is conceivable that this concentration could be attained by inflammation associated with colon carcinoma in situ due to the release of $\mathrm{PGE}_{2}$ by macrophages responding to intestinal microorganism invasion.

Consequently, suboptimal concentrations of $\mathrm{PGE}_{2}$, e.g. $1 \rho \mathrm{M}$, may not be sufficient to maintain epithelial cell differentiation and sustain GJIC; the absence of normal epithelial differentiation and loss of GJIC may contribute to carcinogenesis. Conversely, the presence of excessive concentrations of $\mathrm{PGE}_{2}$, e.g., $1 \mu \mathrm{M}$ (Figure 2), may act to inhibit GJIC, which would also result in carcinogenesis. Measurements done with stromal cell conditioned media using an ELISA kit showed the $\mathrm{PGE}_{2}$ concentration to be in the picomolar range, and maximal GJIC was observed when a similar concentration was applied to normal epithelial cells in vitro (Figure 2).

Besides its effect on normal endometrial epithelial cells, our results also show that $\mathrm{PGE}_{2}$ can cause GJIC to be re-established in the three transformed endometrial epithelial cells lines examined. The concentration of $\mathrm{PGE}_{2}$ required for reestablishing GJIC varied for the three cell lines. It required a 100-fold greater concentration of $\mathrm{PGE}_{2}$ to re-establish GJIC in the FEEC cells as compared to HEC-1A and RL-95-2 cells. The RL-95-2 cells showed a greater response than the HEC-1A cells in terms of the number of cells induced to communicate at the same $\mathrm{PGE}_{2}$ concentrations. HEC-1A cells showed a broader concentration/response effect than FEEC or RL-95-2 cells, but also show a reduced number of cells that re-establish GJIC.

Previous observations and those that we report here suggest features of the mechanism by which GJIC is controlled between endometrial epithelial cells by factors secreted by stromal cells. Endometrial stromal cells produce $\mathrm{PGE}_{2}$ and $\mathrm{PGF}_{2 a}$ under physiological conditions, 
and the amount of $\mathrm{PGE}_{2}$ produced is much greater than $\mathrm{PGF}_{2 a}$ [Gal et al., 1982]. Other studies have shown that the enzymes for metabolism of prostaglandins are almost exclusively located in the endometrial epithelial cells and not in the stromal cells [Casey et al., 1980]. Presumably, stromal cells synthesize and secrete $\mathrm{PGE}_{2}$ into the extracellular milieu and it then diffuses into the epithelial cells where it is metabolized and induces GJIC and a number of other cellular functions. This stromal cell induction of GJIC in epithelial cells is essential to the normal functioning of the epithelium. It is thought that normal GJIC function might suppress progression of carcinogenesis whereas the loss of GJIC between the epithelial cells appears to be a feature of developing malignancies. Consistent with this conjecture is the previous observation that showed normalization of growth control in transformed cells by transfections that increased the amount of connexin proteins and enhanced GJIC [Mehta et al., 1991; Rose et al., 1993].

Other studies done with $\mathrm{PGE}_{2}$ have sought to understand the role of $\mathrm{PGE}_{2}$ regarding labor induction [Adamo, et al., 2001] in a murine model and expression of connexin 43, cyclooxygenases, and $\mathrm{G}_{\mathrm{sa}}$ proteins in the human uterus during pregnancy and labor using myometrial tissue [Cheng et al., 2001]. The studies described in this report only involve interactions between uterine stromal and epithelial cells; myometrial tissue was discarded during tissue processing to isolate primary stromal and epithelial cells. Additionally, studies done with osteocyte-like MLO-4 cells have documented an increase in Cx 43 expression and a small but significant increase in GJIC between these cells occurs in the presence of PGE 2 . This effect was inhibited by treatment with indomethecin and inducible by the stimulatory effect of fluid flow, which causes mechanical strain to the cells [Cook et al., 2000]. However, other studies relating Cx 43 expression in oral-derived human osteoblasts with $\mathrm{PGE}_{2}$ exposure showed no change in Cx 43 expression [Sparey et al., 1999]. In addition, these studies documented that the levels of $\mathrm{Cx} 43$ expression varied significantly from one patient to another and also from which oral bone source the cells were isolated. Overall, our data and the studies of other investigators using different organ systems seem to indicate that connexin expression, GJIC, and the effects of $\mathrm{PGE}_{2}$, if any, appear to be tissue specific.

\section{Conclusions}

Endometrial stromal cells use $\mathrm{PGE}_{2}$ as a paracrine factor to facilitate differentiation (as exemplified by GJIC function) and to inhibit cell proliferation in endometrial epithelial cells. The evolution of endometrial cancer is characterized by a loss of endometrial stroma from between endometrial epithelial glands. We have shown previously that epithelial endometrial cancer cells secrete products that inhibit endometrial stromal and normal epithelial cell growth (Albright and Kaufman, 1995; Albright et al., 1995) and that stromal cells in the absence of hormonal stimulation secrete paracrine products that inhibit endometrial epithelial cell growth (Watson et al., 1995). It is likely that paracrine factors secreted by malignant endometrial epithelial cells cause the observed reduction in the ratio of stromal to epithelial cells seen in endometrial cancer. Consequently the differentiating effects and reduction of cell proliferation that stromal cells normally produce in epithelial cells is lost or greatly reduced during the evolution of endometrial cancers. Because the endometrial epithelial cells in evolving cancers are not constrained by stromal cell paracrine factors because the stromal cells are decreased in number or are absent, cancer development would not require the malignant cells to develop abnormal signaling and regulatory pathways to nullify the inhibitory effects of the stromal cells. Conceivably, endometrial cancer cells retain their responsiveness to stromal-derived paracrine factors that affect GJIC, cell proliferation and other cell functions. Our studies test this concept. While malignant endometrial epithelial cells lose responsiveness to stromal cell regulation by $\mathrm{PGE}_{2}$ as a consequence of transformation, the loss of responsiveness to $\mathrm{PGE}_{2}$ is not complete because a 100 -fold or greater increase in $\mathrm{PGE}_{2}$ can overcome this deficiency. This is significant 
because it suggests a possible new therapeutic approach for treatment of incipient or overt endometrial cancer. Perhaps, prostaglandin-like compounds or compounds that cause increased $\mathrm{PGE}_{2}$ production in the stromal cells could be of benefit in treatment of endometrial carcinomas or might suppress progression of premalignant lesions of the endometrium. Other approaches to cancer therapy via effects on gap junctions and GJIC have been discussed recently (Kandouz and Batist, 2010).

\section{Acknowledgments}

The authors wish to thank Kathy Mohr for her assistance in performing the microinjection studies. This research was supported by research grant R01-CA31733 (DGK) and training Grants F32-CA71138 (SRS) and T32-ES07017 (DGK) from the National Institutes of Health.

\section{Abbreviations}

$\begin{array}{ll}\text { Cx } & \text { connexin } \\ \text { DIC } & \text { differential interference contrast } \\ \text { ELISA } & \text { enzyme linked immunosorbent assay } \\ \text { GJIC } & \text { gap junctional intercellular communication } \\ \text { IL-1 } & \text { interleukin } 1 \\ \text { KDa } & \text { kilodalton } \\ \text { LiCl } & \text { lithium chloride } \\ \text { Min } & \text { Multiple intestinal neoplasia } \\ \text { PGE }_{1} & \text { prostaglandin } \mathrm{E}_{1} \\ \text { PGE }_{2} & \text { prostaglandin } \mathrm{E}_{2} \\ \text { PGF }_{\mathbf{2 a}} & \text { prostaglandin } \mathrm{F}_{2 a}\end{array}$

\section{References}

Adamo CT, Mailhot JM, Smith AK, Borke JL. Connexin-43 expression in oral-derived human osteoblasts after transforming growth factor-beta and prostaglandin E2 exposure. J Oral Implantol. 2001; 27:25-31. [PubMed: 11326538]

Albright CD, Tsongalis GT, Resau JH, Kaufman DG. Human endometrial carcinoma cells release factors which inhibit the growth of normal epithelial cells in culture. Cell Biol and Toxicol. 1995; 11:251-261. [PubMed: 8608406]

Albright CD, Kaufman DG. Transforming growth factor- $\beta 1$ mediates communication between human endometrial carcinoma cells and stromal cells. Pathobiology. 1995; 63:314-319. [PubMed: 8738470]

American Cancer Society. Cancer facts and figures, 2012. Atlanta: American Cancer Society; 2012.

Arnold JT, Kaufman DG, Seppälä M, Lessey BA. Endometrial stromal cells regulate epithelial cell growth in vitro: A new coculture model. Human Repro. 2001; 16:836-845.

Arnold JT, Lessey BA, Seppala M, Kaufman DG. Effect of normal endometrial stroma on growth and differentiation in Ishikawa endometrial adenocarcinoma cells. Cancer Res. 2002; 62:79-88. [PubMed: 11782363]

Baak JP, Mutter GL, Robboy S, van Diest PJ, Uyterlinde AM, Orbo A, Palazzo J, Fiane B, Lovslett K, Burger C, Voorhorst F, Verheijen RH. The molecular genetics and morphometry-based endometrial intraepithelial neoplasia classification system predicts disease progression in endometrial hyperplasia more accurately than the 1994 World Health Organization classification system. Cancer. 2005; 103:2304-2312. [PubMed: 15856484] 
Barbier CS, Becker KA, Troester MA, Kaufman DG. Expression of exogenous human telomerase in cultures of endometrial stromal cells does not alter their hormone responsiveness. Biol Reprod. 2005; 73:106-14. [PubMed: 15772261]

Barbier CS, Kloosterboer HJ, Kaufman DG. Effects of Tibolone on human endometrial cells in coculture. Repro Sci. 2008; 15:75-82.

Beyer EC, Paul DL, Goodenough DA. Topical review: Connexin family of gap junction proteins. J Membrane Biol. 1990; 116:187-194. [PubMed: 2167375]

Bindal RD, Carlson KE, Katzenellenbogen BS, Katzenellenbogen JA. Lipophilic impurities, not phenolsulfonphthalein, account for the estrogenic activity in commercial preparations of phenol red. J Steroid Biochem. 1988; 31:287-293. [PubMed: 3419159]

Casey ML, Hemsell DL, MacDonald PC, Johnston JM. NAD ${ }^{+}$-dependent 15-hydroxyprostaglandin dehydrogenase activity in human endometrium. Prostaglandins. 1980; 19:115-122. [PubMed: 7384534]

Cheng B, Kato Y, Zhao S, Luo J, Sprague E, Bonewald LF, Jiang JX. PGE(2) is essential for gap junction-mediated intercellular communication between osteocyte-like MLO-Y4 cells in response to mechanical strain. Endocrinol. 2001; 142:3464-3473.

Chulada PC, Thompson MB, Mahler JF, Doyle CM, Gaul BW, Lee C, Tiano HF, Morham SG, Smithies O, Langenbach R. Genetic disruption of Ptgs-1, as well as of Ptgs-2, reduces intestinal tumorigenesis in Min mice. Cancer Res. 2000; 60:4705-4708. [PubMed: 10987272]

Cook JL, Zaragoza DB, Sung DH, Olson DM. Expression of myometrial activation and stimulation genes in a mouse model of preterm labor: myometrial activation, stimulation, and preterm labor. Endocrinol. 2000; 141:1718-1728.

Cronier L, Crespin S, Strale P-O, Defamie N, Mesnil M. Gap junctions and cancer: New functions for an old story. Antioxid Redox Signal. 2009; 11:323-338. [PubMed: 18834328]

Fitzgerald DJ, Fusenig NE, Boukamp P, Piccoli C, Mesnil M, Yamasaki H. Expression and function of connexins in normal and transformed human keratinocytes in culture. Carcinogenesis. 1994; 15:1859-1865. [PubMed: 7923578]

Gal D, Casey ML, Johnston JM, MacDonald PC. Mesenchyme-epithelial interactions in human endometrium: Prostaglandin synthesis in separated cell types. J Clin Invest. 1982; 70:798-805. [PubMed: 6811614]

Hopfer H, Rinehart CA Jr, Vollmer G, Kaufman DG. In vitro interactions of endometrial stromal and epithelial cells in Matrigel: reorganization of the extracellular matrix. Pathobiology. 1994; 62:104108. [PubMed: 7945912]

Kandouz M, Batist G. Gap junctions and connexins as therapeutic targets in cancer. Expert Opin Ther Targets. 2010; 14:681-692. [PubMed: 20446866]

Klann RC, Fitzgerald DJ, Piccoli C, Slaga TJ, Yamasaki H. Gap-junctional intercellular communication in epidermal cell lines from selected stages of SENCAR mouse skin carcinogenesis. Cancer Res. 1989; 49:699-705. [PubMed: 2463079]

Kuramoto H, Tamura S, Notake Y. Establishment of a cell line of human endometrial carcinoma in vitro. Am J Obstet Gynecol. 1972; 114:1012-1019. [PubMed: 4673779]

Larsen WJ, Risinger MA. The dynamic life histories of intercellular membrane junctions. Modern Cell Biol. 1985; 4:151-216.

Leithe E, Simes S, Omori Y, Rivedal E. Downregulation of gap junctions in cancer cells. Crit Rev Oncog. 2006; 12:225-256. [PubMed: 17425504]

Lui CH, Chang SH, Narko K, Trifan OC, Wu MT, Smith E, Haudenschild C, Lane TF, Hla T. Overexpression of cyclooxygenase- 2 is sufficient to induce tumorigenesis in transgenic mice. $\mathrm{J}$ Biol Chem. 2001; 276:18563-18569. [PubMed: 11278747]

Mesnil M, Crespin S, Avanzo JL, Zaidan-Dagli ML. Defective gap junctional intercellular communication in the carcinogenic process. Biochim Biophys Acta. 2005; 1719:125-145. [PubMed: 16359943]

Mazur MT. Endometrial hyperplasia/adenocarcinoma. a conventional approach. Ann Diagn Pathol. 2005; 9:174-181. [PubMed: 15944963] 
Mehta PP, Hotz-Wagenblatt A, Rose B, Shalloway D, Loewenstein WR. Incorporation of the gene for a cell-cell channel protein into transformed cells leads to normalization of growth. J Membrane Biol. 1991; 124:207-225. [PubMed: 1664859]

Nicholson GL, Dulski KM, Trosko JE. Loss of intercellular junctional communication correlates with metastatic potential in mammary adenocarcinoma cells. Proc Natl Acad Sci USA. 1988; 85:473476. [PubMed: 3422438]

Radu A, Dahl G, Loewenstein WR. Hormonal regulation of cell junction permeability: Upregulation by catecholamine and prostaglandin $\mathrm{E}_{1}$. J Membrane Biol. 1982; 70:239-251. [PubMed: 6313926]

Revel J-P, Nicholson BJ, Yancey SB. Chemistry of gap junctions. Ann Rev Physiol. 1985; 47:263279. [PubMed: 2986531]

Rinehart CA Jr, Lyn-Cook BD, Kaufman DG. Gland formation from human endometrial epithelial cells in vitro. In Vitro Cell and Develop Biol. 1988; 24:1037-1041.

Roberts DK, Walker NJ, Lavia LA. Ultrastructural evidence of stromal/epithelial interactions in the human endometrial cycle. Am J Obstet Gynecol. 1988; 158:854-861. [PubMed: 3364498]

Rose B, Mehta PP, Loewenstein WR. Gap-junction protein gene suppresses tumorgenicity. Carcinogenesis. 1993; 14:1073-1075. [PubMed: 8389252]

Ruch RJ, Klaunig JE. Kinetics of phenobarbital inhibition of intercellular communication in mouse hepatocytes. Cancer Res. 1988; 48:2519-2523. [PubMed: 3356013]

Sano H, Kawahito Y, Wilder RL, Hashiramoto A, Mukai S, Asai K, Kimura S, Kato H, Kondo M, Hla T. Expression of cyclooxygenase-1 and -2 in human colorectal cancer. Cancer Res. 1995; 55:3785-3789. [PubMed: 7641194]

Schlemmer SR, Kaufman DG. Regulation of connexon function in human endometrial epithelial cells by stromal cells: Loss of regulation after epithelial cell carcinogenesis: Loss of regulation after epithelial cell carcinogenesis. Mol Carcinogenesis. 2000; 28:70-75.

Schlemmer SR, Novotny DB, Kaufman DG. Changes in connexin 43 protein expression in humanendometrial carcinoma. Exper 1 and Molec Pathol. 1999; 67:150-163.

Sparey C, Robson SC, Bailey J, Lyall F, Europe-Finner GN. The differential expression of myometrial connexin-43, cyclooxygenase-1 and -2 , and Gs alpha proteins in the upper and lower segments of the human uterus during pregnancy and labor. J Clin Endocrinol Metab. 1999; 84:1705-1710. [PubMed: 10323404]

Spray DC. Special topic: Gap junctions. Ann Rev Physiol. 1985; 47:261-262.

Trosko JE. The role of stem cells and gap junctional intercellular communication in carciongenesis. J Biochem Molec Biol. 2003; 36:43-48. [PubMed: 12542974]

Vinken M, Doktorova T, Decrock E, Leybaert L, Vanhacke T, Rogiers V. Gap junctional intercellular communication as a target for liver toxicity and carcinogenicity. Crit Rev Biochem Molec Biol. 2009; 44:201-222. [PubMed: 19635038]

Way DL, Grosso DS, Davis JR, Surwit EA, Christian CD. Characterization of a new human endometrial carcinoma (RL-95-2) established in tissue culture. In Vitro. 1983; 19:147-158. [PubMed: 6339371]

Watson JM, Lofquist AK, Rinehart CA, Olsen J, Makarov SS, Kaufman DG, Haskill JS. The intracellular IL-1 receptor antagonist alters IL-1 inducible gene expression without blocking exogenous signaling by IL-1 $\beta$. J Immunol. 1995; 155:4467-4475. [PubMed: 7594609]

Yamasaki H, Mesnil M, Omori N, Krutovskikh V. Intercellular communication and carcinogenesis. Mut Res. 1995; 333:181-188. [PubMed: 8538626] 


\section{Highlights}

- Endometrial epithelial and stromal cells in co-culture reproduce tissue functions in vivo

- Stromal cells in co-culture activate GJIC in normal endometrial epithelial cells

- Conditioned medium can replace stromal cells in co-cultures for activating GJIC

- Stromal cell conditioned medium does not restore GJIC in epithelial cancer cells

- Prostaglandin $\mathrm{E}_{2}$ in medium induced GJIC activity in normal epithelial cells

- Prostaglandin $\mathrm{E}_{2}$ restored some GJIC activity in epithelial cancer cells 

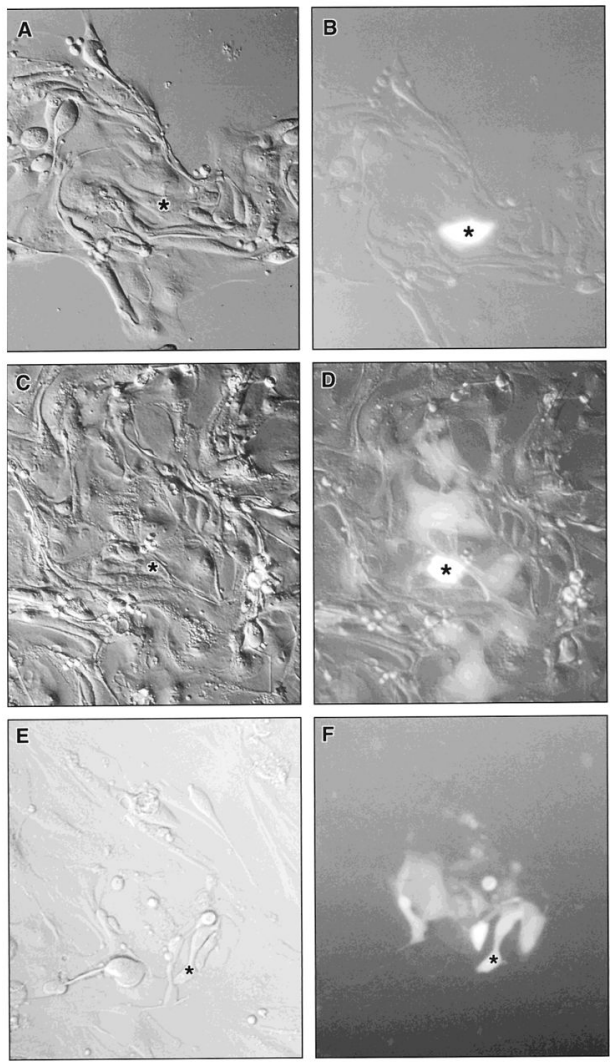

Figure 1.

Lucifer yellow dye coupling assay of normal epithelial cells cultured alone, cultured with medium conditioned, and co-cultured with stromal cells. The black asterisk marks the donor cell that was injected with Lucifer yellow. 1A. Differential interference contrast (DIC) photo of normal epithelial cells ${ }^{\mathrm{a}}$. 1B. Epifluorescence photo of cells shown in 1A five minutes after microinjection with Lucifer yellow. 1C. DIC photo of normal epithelial cells cultured with medium conditioned by stromal cells ${ }^{\mathrm{a}}$. 1D. Epifluorescence photo of cells shown in 1C five minutes after microinjection with Lucifer yellow. 1E. DIC photo of normal epithelial cells co-cultured with stromal cells ${ }^{\mathrm{a}}$. 1F. Epifluorescence photo of cells shown in 1E five minutes after microinjection with Lucifer yellow. ${ }^{\text {aThese }}$ photos were published previously [Schlemmer and Kaufman, 2000]. 


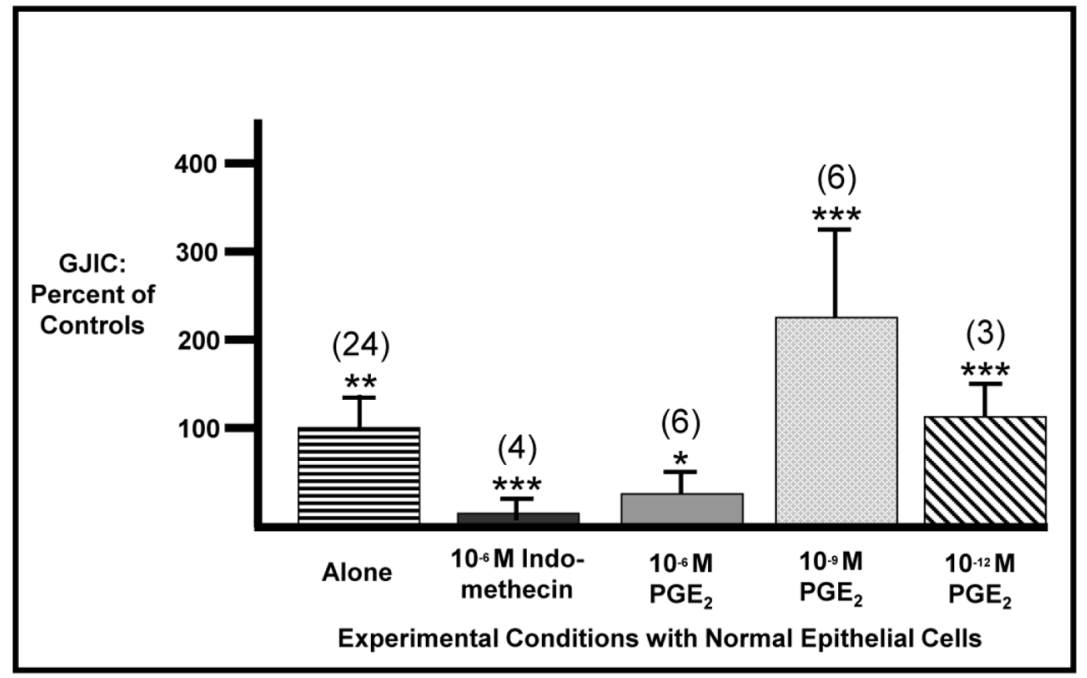

Figure 2.

The effect of the concentration of $\mathrm{PGE}_{2}$ on GJIC between normal endometrial epithelial cells. The percentage of epithelial cells showing GJIC (using epithelial cells alone as 100\%) is shown by the height of the bar graphs under the experimental condition is shown in parentheses above the asterisks. The statistical probability $(p)$ is shown by the number of asterisks above each standard deviation upper bound, and are expressed as: * $p<0.05 ; * * p$ $<0.01$; and $* * * p<0.001$. The number of individual experiments $(\mathrm{n})$ for each condition is shown in parentheses above the asterisks. 

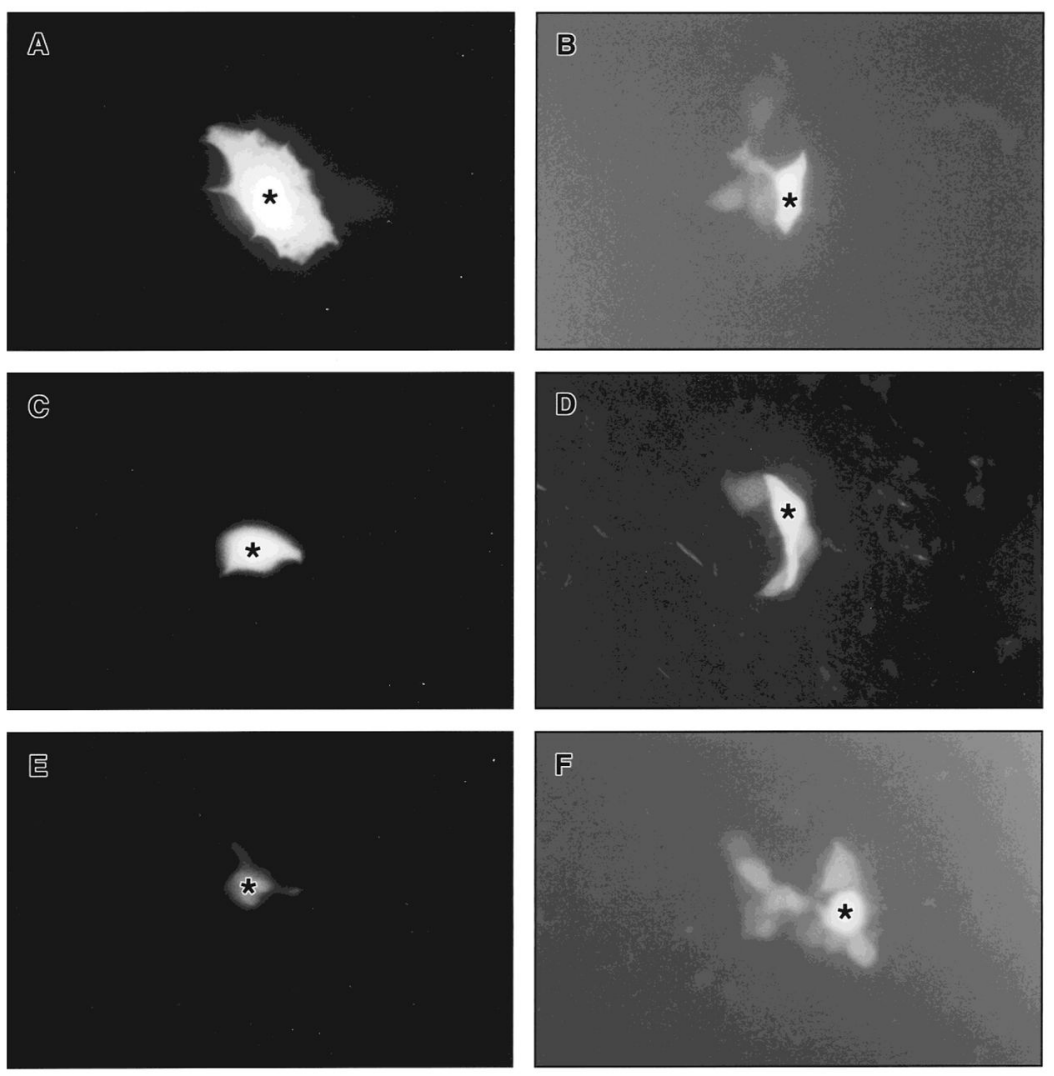

Figure 3.

Lucifer yellow microinjection of FEEC, HEC-1A, and RL-95-2 transformed epithelial cells alone and with the concentration of $\mathrm{PGE}_{2}$ that produced the maximum amount of GJIC. The black asterisk marks the dye donor cell. The photos were taken five minutes after microinjection with Lucifer yellow. 3A. Epifluorescence photo of FEEC cells alone. 3B. Epifluorescent photo of FEEC cells with $10 \mu \mathrm{M} \mathrm{PGE}_{2}$. 3C. Epifluorescence photo of HEC-1A cells alone. 3D. Epifluorescent photo of HEC-1A cells with $100 \mathrm{nM} \mathrm{PGE} 2.3 E$. Epifluorescence photo of RL-95-2 cells alone a $\mathbf{3 F}$. Epifluorescent photo of RL-95-2 cells with $100 \mathrm{nM} \mathrm{PGE}{ }_{2}{ }^{\mathrm{a}}$. ${ }^{\mathrm{a}}$ These photos were published previously [Schlemmer and Kaufman, 2000]. 


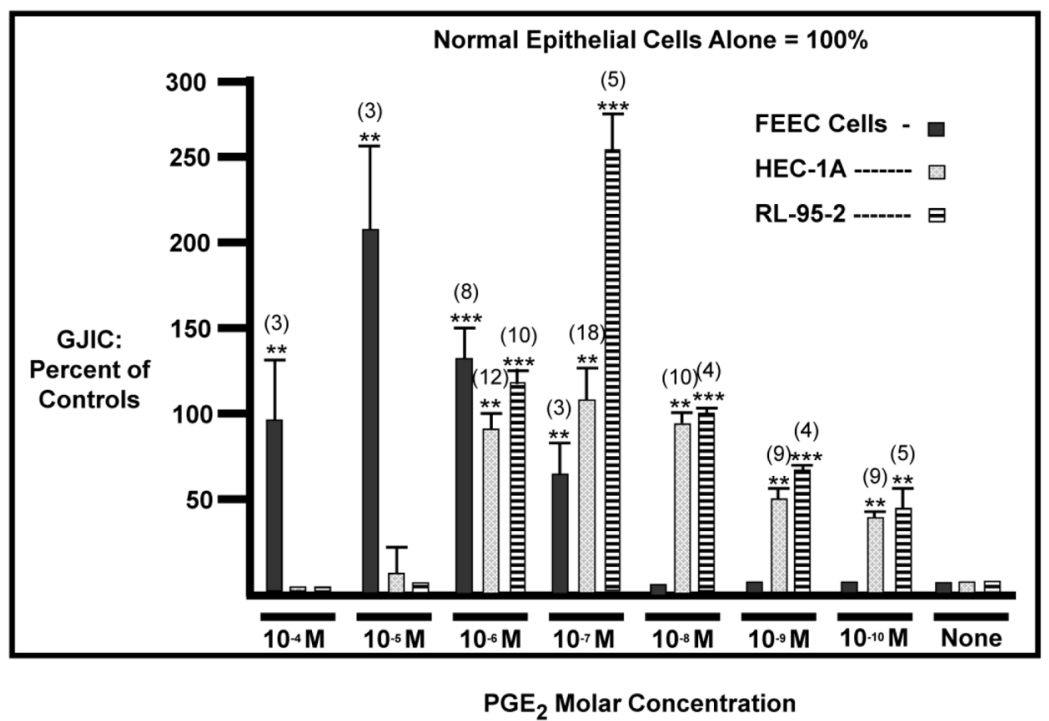

Figure 4.

Concentration/response of $\mathrm{PGE}_{2}$ on GJIC between transformed epithelial cells. The percentage of transformed epithelial cells showing GJIC (using normal epithelial cells alone as $100 \%$ ) is shown by the height of the bar graphs and the $\mathrm{PGE}_{2}$ concentrations below each set of bars. The results from the FEEC cells are shown as white bars, HEC-1A as gray bars, and RL-95-2 as black bars. The standard error of the mean is shown by the T-shaped symbols on top of each bar. The statistical probability $(p)$ is shown by the number of asterisks above each standard deviation upper bound, and are expressed as: * $p<0.05 ; * * p$ $<0.01$; and $* * * p<0.001$. The number of individual experiments $(\mathrm{n})$ for each condition is shown in parentheses above the asterisks. 
TABLE 1

\begin{tabular}{lcrl}
\hline Epithelial Cells Cultured & Average Number of Cells Showing GJIC ( \pm SD) & $\mathbf{n}$ & $\mathbf{P}^{\boldsymbol{a}}$ \\
\hline Alone & $1.0(1.0)$ & 24 & $0.0025^{b, e}$ \\
With Stromal Cells Present & $3.2(2.2)$ & 25 & $0.00044^{c, e}$ \\
With Stromal-Cell-Conditioned Medium & $2.5(1.9)$ & 6 & $0.0094^{d}$ \\
\hline${ }^{a}$ Statistical significance determined by Student's t test & & \\
${ }^{b}$ Epithelial cells cultured alone vs. malignant epithelial cells cultured alone & & \\
${ }^{c}$ Epithelial cells cultured alone vs. epithelial cells co-cultured with stromal cells & & \\
${ }^{d}$ Epithelial cells cultured with stromal-cell-conditioned medium vs. epithelial cells cultured without stromal cell conditioned medium \\
$e_{\text {These data were published previously [Schlemmer and Kaufman, 2000]. }}$
\end{tabular}

Exp Mol Pathol. Author manuscript; available in PMC 2013 December 01. 